\title{
A desmistificação da concepção das regras matemáticas: uma análise a partir da filosofia da linguagem de Wittgenstein
}

\author{
The demystification of the conception of mathematical rules: an analysis as of \\ Wittgenstein's philosophy of language
}

\author{
Marcel de Almeida Barbosa ${ }^{1}$
}

\section{Resumo}

Este artigo tem como objetivo desmistificar a concepção presente em trabalhos da educação matemática segundo a qual o ensino das regras matemáticas torna 0 aprendizado um processo mecânico. A finalidade é contribuir para o processo educativo da disciplina, em um cenário onde atuam professor e alunos sob a perspectiva da Filosofia de Wittgenstein. A linguagem matemática é regida por regras e é dever do professor ensiná-las, bem como dar sentido às regras implícitas no texto matemático, seja ele escrito em linguagem simbólica, seja em linguagem natural. Explicitamos o processo de aplicação de regras, pois algumas pesquisas em educação matemática apontam que o seu uso torna o ensino e aprendizagem mecânicos. Portanto, ressaltamos que, para haver a compreensão do conceito matemático, é imprescindível que a comunicação entre professor e aluno seja estabelecida, pois a comunicação das regras matemáticas dá-se a partir da linguagem natural do aluno.

Palavras-chave: Regras Matemáticas. Uso de Regras. Ensino de Matemática. Linguagem Matemática

\section{Abstract}

This article aims to demystify the conception present in mathematical education works according to which the teaching of mathematical rules makes learning a mechanical process. The purpose is to contribute to the educational process of the discipline, in a setting where teachers and students act from the perspective of Wittgenstein's philosophy. Mathematical language is governed by rules and it is the teacher's duty to teach them, as well as to make sense of the rules implicit in the mathematical text, whether written in symbolic or natural language. We explain the process of applying rules, because some research in mathematics education indicates that its use makes teaching and learning mechanical. Therefore, we emphasize that, in order to understand the mathematical concept, it is essential that the communication between teacher and student is established, because the communication of mathematical rules is based on the student's natural language.

\footnotetext{
1 Mestrando pelo Programa de Pós-Graduação em Educação em Ciências e Matemáticas (PPGECM/UFPA),Docente de Matemática na Prefeitura Municipal de Afuá, mab_marcel@hotmail.com
} 
Keywords: Mathematical Rules. Use of Rules. Mathematics teaching. Mathematical Language

\section{Introdução}

A Educação Matemática possui linhas de estudos e pesquisas que visam a melhorar o ensino e a aprendizagem da Matemática, sobretudo, na educação básica. Logo, debruçamo-nos sobre os estudos sobre Linguagem Matemática para pesquisar a respeito dos possíveis problemas de compreensão da linguagem que permeiam o processo educativo da disciplina. Para Silveira (2015), o aluno tem dificuldades de interpretar a linguagem simbólica, bem como as regras matemáticas que regem tanto o texto em linguagem natural quanto em linguagem matemática.

Este artigo traz um recorte da minha pesquisa de dissertação de mestrado em andamento e tem por objetivo desmistificar a concepção de que o ensino das regras matemáticas torna o aprendizado um processo mecânico, em razão de esta estar presente em trabalhos da educação matemática, tal como nas considerações abaixo:

Apesar dos avanços do ensino da matemática no ensino fundamental, o ensino de frações continua se caracterizando por uma prática voltada para aprendizagem mecânica do algoritmo constituindo-se em um desafio aos professores que procuram desenvolver uma real compreensão desse conceito em seus alunos. (MACHADO, 2007, p. 15).

Nos deparamos muitas vezes, com o ensino mecânico, cheio de regras, que nem o professor e nem os alunos sabem para que serve. [...] $O$ ensino mecânico é uma das causas nas deficiências encontradas na formação do aluno no ensino fundamental I, deixando lacunas em seu conhecimento e uma defasagem matemática de difícil reconstrução posterior. (SCHIMITZ, 2017, p. 5215).

A partir dos excertos surge o questionamento: será que o processo de aplicação da regra é mecânico? Por ter uma linguagem própria, a matemática precisa fazer sentido para o aluno desde o início da escolarização, pois, de acordo com Silveira (2015), o ensino de matemática com ênfase na linguagem propicia a comunicação entre aluno e professor. Nesse sentido, é preciso que a linguagem do 
professor esclareça os significados dos símbolos matemáticos, bem como as regras matemáticas que governam o texto matemático.

Como educadora matemática afiliada à filosofia da linguagem de Wittgenstein, Silveira (2015) ressalta que os jogos de linguagem, principal conceito da obra do filósofo ${ }^{2}$, podem auxiliar a elucidar os problemas de ordem linguística que permeiam a linguagem codificada da matemática. Isso pode se dar através da comunicação entre professor e aluno, por meio da qual é possível dissolver os problemas encontrados no uso da linguagem e na compreensão das regras que governam os enunciados matemáticos. Para tanto, professor e aluno devem participar do mesmo universo discursivo, para que as palavras pronunciadas tenham um mesmo significado, tenham uma forma de vida (SILVEIRA, 2017).

$O$ artigo baseia-se na filosofia da linguagem de Wittgenstein, sobretudo, na obra Investigações Filosóficas (IF), e traz algumas reflexões acerca do conceito de seguir regras, que pode contribuir na prática da sala de aula do professor que ensina matemática. Em um primeiro momento, este texto aborda o conceito wittgensteiniano de seguir regras e suas particularidades; em um segundo momento, discute-se acerca do processo de aplicação de regras matemáticas no contexto da sala de aula; em seguida, fala-se sobre a importância do uso de regras matemáticas no ensino de matemática; por fim, tecem-se algumas considerações acerca das ideias discutidas no artigo.

\section{Seguir regras em Wittgenstein}

As regras estão na nossa vida cotidiana, como nas regras de trânsito, regras de comportamento, regras de um jogo de tabuleiro etc. As ações do sujeito devem estar de acordo as regras, já que informam as ações esperadas, de modo que, quando o indivíduo não age com base nas regras, há consequências. Por exemplo: caso infrinja uma regra de trânsito, poderá ser multado; se desobedecer a uma

\footnotetext{
${ }^{2}$ De acordo com comentadores, a filosofia de Wittgenstein pode ser dividida em duas fases: a primeira, em Tratactus, e a segunda, em Investigações Filosóficas. Para este artigo, a obra adota é da segunda fase.
} 
regra de etiqueta, o sujeito será visto como mal-educado, indelicado; se não seguir a regra do jogo, não se está a jogar. As regras são padrões de correção para que o sujeito em sociedade saiba o que é correto ou não em uma determinada situação, porém, as regras podem ser refutáveis, questionáveis, até anuláveis, ainda que nunca possam ser suprimíveis em sociedade.

Na obra Investigações Filosóficas, a linguagem é uma atividade guiada por regras, e o caráter apriorístico da lógica, da matemática e da filosofia provém dessas regras (GLOCK, 1998, p. 312).

Wittgenstein preocupou-se em analisar as regras da gramática, pois são elas que determinam o significado das palavras, razão pela qual, quando não há o cuidado quanto ao jogo de linguagem em que se está inserido e às regras gramaticais desse jogo, pode haver confusões linguísticas. Ele diz que não "devese cortar o galho no qual está sentado" (WITTGENSTEIN, 1996, § 55), o que equivaleria a rejeitar as regras gramaticais.

Para o filósofo, "todo signo sozinho parece morto. O que lhe dá vida? No uso ele vive" (WITTGENSTEIN, 1996, § 432). A gramática da palavra "xadrez", por exemplo, implicitamente possui regras para se jogar com as peças constituintes do jogo. A peça "cavalo" no jogo é a única que pode "saltar" sobre as demais peças, andar duas casas consecutivas e depois mais uma casa (no sentido perpendicular), assim tendo um movimento semelhante à letra L. Porém, se pegarmos a mesma peça e a levarmos para um outro jogo de tabuleiro, ela não será regida pelas mesmas regras de outrora, pois a peça não carrega consigo o significado; assim, a peça em outro contexto será regida por regras próprias. É no uso que ela adquire significado.

O seguir regras para Wittgenstein, seja no uso das palavras, seja na Matemática, assemelha-se a seguir uma ordem. "O ato de fazer uma comunicação, dar uma ordem, jogar uma partida de xadrez são hábitos, costumes, instituições" (WITTGENSTEIN, 1996, § 199). Sendo uma instituição, não é concebível que somente uma única pessoa tenha seguido a regra, pois o que constitui a regra é o uso coletivo, a prática constante dela. 
De acordo com Wittgenstein, conforme esclarece nas Investigações Filosóficas, seguir uma regra é uma práxis. Dessa forma, acreditar seguir a regra não é seguir a regra. Daí não podemos seguir a regra "privadamente", porque, senão, acreditar seguir a regra seria o mesmo que seguir a regra (WITTGENSTEIN, 1996, § 202). Assim, a regra precisa ser compreendida, e compreensão na acepção do filósofo é dominar uma técnica, é uma habilidade, de modo que é na prática que ela se constitui. Quando o sujeito segue a regra privadamente, não há uma prática, pois esta determina se a aplicação da regra está correta ou incorreta, assim como há critérios públicos para correção, sendo o costume (prática, hábito) o pano de fundo para seguir a regra; caso este seja removido, a regra não existe.

$\mathrm{Na}$ tentativa de refutar ceticamente o que seria "seguir uma regra", Krippke (apud SILVA, 2010) afirma que, se retirássemos das regras todo o seu poder compulsivo, haveria entre a regra e sua aplicação um fosso verdadeiramente intransponível. Para qualquer tentativa de fechá-lo, seria necessária a interpretação da regra, uma interpretação que daria suporte a outra interpretação e assim sucessivamente.

Wittgenstein esclarece que "cada interpretação, juntamente com 0 interpretado, paira no ar; ela não pode servir de apoio a este" (WITTGENSTEIN, 1996, § 19). Desta maneira, o abismo ou fosso entre uma regra e sua aplicação é transporto por nossas práticas, na medida em que a atividade de seguir uma regra é essencialmente uma prática (GLOCK, 1998, p. 315).

Desta maneira, o filósofo explica que:

É comunicada àquele que aprende e sua aplicação é exercitada. [...] Aprendese o jogo observando como os outros jogam. Mas dizem que se joga segundo esta ou aquela regra, porque um observador pode ler essas regras nas práxis do jogo, como uma lei natural que as jogadas seguem. Mas como o observador distingue, nesse caso, entre um erro de quem joga e uma jogada certa? Há para isso indícios no comportamento dos jogadores. Pense no comportamento característico daquele que comete um lapso. Seria possível reconhecer que alguém faça isso, mesmo que não compreenda sua linguagem. (WITTGENSTEIN, 1996, § 54).

Em um transporte público no Brasil, como o ônibus, é preciso "puxar" a corda para sinalizar como significado que queremos descer na próxima parada, assim 
como em outros países basta apertar um botão e, em outros, o motorista para em todas as paradas automaticamente. Neste caso, para a correta aplicação da regra seria necessária uma interpretação? Não. É importante ressaltar que o ato de "puxar" a corda não é uma regra privada, que somente uma pessoa faz. Esta regra é pública e comumente praticada por muitas pessoas nas grandes cidades.

A este caso de regra, o indivíduo pode dizer: "fui treinado para reagir de uma determinada maneira a este signo e agora reajo assim" (WITTGENSTEIN, 1996, § 198). O usuário foi ensinado por alguém e/ou observou a ação de outros passageiros, na medida em que houve um costume, um hábito da regra. Em outras palavras, dentro dos jogos de linguagem primários, o sujeito seguiu a regra cegamente.

Recorremos ao exemplo dado por Dall'Agnol (2003) para ainda falarmos sobre a interpretação dada à regra:

Um professor escreveu na lousa a série numérica: 1, 4, 9, 16 e pediu a dois alunos que indicassem o próximo número da série. $\mathrm{O}$ aluno 1 interpretou a regra a partir do conhecimento de potenciação, assim:

$$
\begin{gathered}
1=1^{2} \\
4=2^{2} \\
9=3^{2} \\
16=4^{2} \\
25=5^{2}
\end{gathered}
$$

Logo, a sequência seria 1, 4, 9, 16, 25.

O aluno 2 deu outra explicação a partir dos números primos $(3,5,7,11)$, em que se soma o número primo com o valor anterior da sequência:

$$
\begin{aligned}
& 1 \\
& 4=1+3 \\
& 9=4+5 \\
& 16=9+7 \\
& 27=16+11
\end{aligned}
$$


Neste exemplo, vimos que, dada a regra pelo professor para que ambos os estudantes completassem o próximo número da série, houve a necessidade de uma interpretação. Porém, a interpretação não foi suficiente para correta aplicação da regra, uma vez que ambos tiveram respostas distintas. Para Wittgenstein (WITTGENSTEIN, 1996, §198), "as interpretações não determinam sozinhas a significação", e a interpretação (WITTGENSTEIN, 1996, §201) "se manifesta, em cada caso de seu emprego, naquilo que chamamos de seguir regra".

Destes trechos, depreendemos que para a compreensão concernente à regra dada pelo professor era imprescindível informar em qual elemento do contexto matemático o problema estava inserido. Uma vez indicado o elemento importante do contexto - por exemplo, que a aula se deu a partir do conceito de potenciação -, logo, saberíamos identificar qual aluno seguiu corretamente a regra.

A partir dos exemplos expostos, retornamos para dar uma solução ao problema que Krippke levantou quanto à necessidade de uma interpretação para justificar cada passo da regra. A partir do exemplo anterior, esta justificativa não tem sentido, pois "todo agir segundo a regra é uma interpretação" (WITTGENSTEIN, 1996, § 201). Assim, o filósofo esclarece que a obtenção da real interpretação dá-se a partir do contexto, pois é lá que os sujeitos praticam a regra, é no uso que ela adquire sentido. "Apenas indiquei que alguém somente se orienta por um indicador de direção na medida em que haja um uso contínuo, um hábito" (WITTGENSTEIN, 1996, § 198). Ele esclarece ainda que uma regra se apresenta como um indicador de direção (WITTGENSTEIN, 1996, § 85).

Silveira (2015) chama atenção para o fato de que seguir uma regra é uma capacidade técnica. Porém, a regra não é mecânica, porque ela não contém todos os casos de sua aplicação, que se encontram dentro da gramática da nossa linguagem. A regra não é apreendida de uma só vez, ela surge de uma prática constante. Desta maneira, Wittgenstein sustenta a fala da autora quando diz que uma regra se apresenta como um indicador de direção e que este não deixa subsistir nenhuma dúvida. Assim, isso já não é uma proposição filosófica, mas uma 
proposição empírica. Logo, o sujeito pode saber aplicar a regra num contexto, mas pode ter dúvidas de como aplicá-la em um novo contexto.

Na perspectiva da Educação Matemática, há três elementos importantes em uma sala de aula: o professor, o aluno e a matemática. Ao falarmos de regras, uma pergunta surge: quando mudamos de um contexto (matemático) para outro contexto, tal como do conjunto dos números reais para o conjunto dos números complexos, mudam-se as regras matemáticas? A seguir discutiremos como as regras comportam-se no ensino e na aprendizagem da Matemática.

\section{A aplicação da regra matemática}

Pela definição de derivada de uma função real no ponto $x_{0}$, calculamos a derivada da função $f(x)=3 x+4$.

Logo,

$$
\begin{aligned}
f^{\prime}\left(x_{0}\right) & =\lim _{x \rightarrow x_{0}} \frac{f(x)-f\left(x_{0}\right)}{x-x_{0}} \\
f^{\prime}\left(x_{0}\right) & =\lim _{x \rightarrow 2} \frac{f(x)-f(2)}{x-2} \\
f^{\prime}\left(x_{0}\right) & =\lim _{x \rightarrow 2} \frac{3 x+4-10}{x-2} \\
f^{\prime}\left(x_{0}\right) & =\lim _{x \rightarrow 2} \frac{3 x-6}{x-2} \\
f^{\prime}\left(x_{0}\right) & =\lim _{x \rightarrow 2} \frac{3(x-2)}{(x-2)} \\
f^{\prime}\left(x_{0}\right) & =\lim _{x \rightarrow 2} 3 \\
f^{\prime}\left(x_{0}\right) & =3
\end{aligned}
$$

Pela regra de derivação de uma função real do tipo $f(x)$, temos que $\mathrm{f}_{1}(\mathrm{x})=$ $x^{n}, \operatorname{assim} f^{\prime}{ }_{1}(x)=x^{n-1}$ e $f_{2}(x)=k$, k é uma constante, então $f^{\prime}{ }_{2}(x)=0$. Portanto, $f(x)=$ $3 x+4$, sua derivada é $f^{\prime}(x)=3$.

Pela definição de derivada uma função complexa no ponto $z_{0}$, calculamos a derivada da função $g(z)=3 z+4$.

Logo, 


$$
\begin{aligned}
g^{\prime}\left(z_{0}\right) & =\lim _{z \rightarrow z_{0}} \frac{f(z)-f\left(z_{0}\right)}{z-z_{0}} \\
g^{\prime}\left(z_{0}\right) & =\lim _{z \rightarrow 2} \frac{f(z)-f(2)}{z-2} \\
g^{\prime}\left(z_{0}\right) & =\lim _{z \rightarrow 2} \frac{3 z+4-10}{z-2} \\
g^{\prime}\left(z_{0}\right) & =\lim _{z \rightarrow 2} \frac{3 z-6}{z-2} \\
g^{\prime}\left(z_{0}\right) & =\lim _{z \rightarrow 2} \frac{3(z-2)}{(z-2)} \\
g^{\prime}\left(z_{0}\right) & =\lim _{z \rightarrow 2} 3 \\
g^{\prime}\left(z_{0}\right) & =3
\end{aligned}
$$

A regra de derivação de uma função complexa do tipo $g(x)$ é análoga à regra de uma função real. Logo, se $g(x)=3 z+4$, implica dizer que $g^{\prime}(x)=3$.

Vimos que a regra matemática é a mesma, porém, os contextos matemáticos são distintos, ora definido no conjunto dos números reais, ora no conjunto dos números complexos. Há outro caso de regra, o qual Silveira (2015) aponta que no processo de aplicação de regra, dá-se quando o aluno se depara com contextos diferentes e a regra, que deveria ser a mesma, passa por transformações e é por ele modificada.

Pela fala da autora, vemos que isso acontece em sala de aula. Durante minha experiência docente, um aluno do $8^{\circ}$ ano do ensino fundamental resolveu o produto notável $(x+y)^{2}=x^{2}+2 x y+y^{2}$. No entanto, ao se deparar com outro produto notável $(\sqrt{x}+\sqrt{y})^{2}$, este o resolveu pensando ser apenas uma simplificação da radiciação, onde: $(\sqrt{x})^{2}=x$, para todo $\mathrm{x} \geq 0$. Logo, para este aluno: $(\sqrt{x}+\sqrt{y})^{2}=(\sqrt{x})^{2}+(\sqrt{y})^{2}=x+y$. O aluno normalmente não consegue perceber (sozinho) que há uma relação entre os dois contextos e que poderá usar a mesma regra. É importante que o professor mostre ao aluno que uma regra pode ser aplicada em diferentes contextos, explorando vários exemplos para que o aluno possa compreender o conceito matemático. 
Silveira (2015) também apresenta situações nas quais o aluno cria regras a partir de um conteúdo já aprendido. Ele sabe que $2+3=5$ e, desse pressuposto, conclui que $\frac{1}{2}+\frac{1}{3}=\frac{1}{5}$ e $\sqrt{2}+\sqrt{3}=\sqrt{5}$. O aluno faz analogias e essas analogias derivam em erro. Ele estabelece critérios para fazer julgamento através do que percebe e do que vê.

As regras matemáticas possuem regras próprias. Para o aluno, ao interpretar a regra, é necessário que esteja de acordo com a lógica matemática e não com sua própria lógica. Por este motivo, o professor que ensina matemática deve pautar-se a partir do diálogo, ouvir o aluno, dar oportunidades para que ele verbalize. Tratase de um momento em que o professor poderá saber se o aluno está compreendendo o conceito ou não.

Para tanto, Silveira (2013) nos dá um exemplo quanto à problemática na aplicação de regras matemáticas, em que, ao ensinar classe e ordem dos numerais, o professor tem como exemplo o 425 e explica à turma: o cinco é unidade, o dois é dezena e o quatro é centena. Ao escrever no quadro o 254, ouve a reposta da turma: o cinco é unidade, o dois é dezena e o quatro é centena. Neste momento ele percebe que houve uma falha na comunicação ao ensinar. Tanto o professor quanto o aluno precisam estar de acordo com a lógica da matemática, seguir a gramática da matemática.

Outro aspecto do uso da regra se dá quando o aluno interpreta e aplica a regra num determinado conteúdo a partir de um outro já estudado, no intuito de construir o sentido coerente para aplicação correta da regra nesse novo contexto. No entanto, ele acaba transgredindo a regra; isso ocorre porque ele tenta fazer analogias com as regras já estudadas e estas apresentam semelhanças. Esse (re)interpretar da regra em um novo contexto matemático, ao menos, indica que o aluno tem domínio da aplicação de regra.

Como exemplo, temos as funções $f(x)=\ln (x)$ e $f(x)=\ln \left(x^{3}+2 x^{2}\right)$. No exercício de calcular as regras de derivadas, o aluno pode fazer analogia do resultado da primeira com $f^{\prime}(x)=\frac{1}{x} \operatorname{com}$ a segunda e dar como resposta $f^{\prime}(x)=$ 
$\frac{1}{x^{3}+2 x^{2}}$. No entanto, ele não percebeu que no segundo caso a regra de derivada é outra, uma vez que temos uma função composta e utilizamos a regra da cadeia. Portanto, a resposta seria $f^{\prime}(x)=\frac{3 x^{2}+4 x}{x^{3}+2 x^{2}}$.

De acordo com o exemplo, Silveira (2015) aponta que o aluno compreende que existe uma semelhança sintática e uma correspondência teórica entre os dois termos. Porém, ele pode não seguir a regra corretamente, modificando e causando prejuízo ao conceito idealizado pela exigência teórica, ao fazer conexões com outros conceitos. Wittgenstein não se preocupou em fazer teoria, sua filosofia aponta caminhos concernentes ao ensino de matemática sob a luz dos jogos de linguagem, o qual denomina como o conjunto da linguagem e das atividades com as quais está interligada. Para ele, traduzir de uma língua para outra é um jogo de linguagem, assim como comandar e agir segundo comandos.

\section{A importância do uso de regras no ensino de matemática}

A Matemática é governada por regras e o seu ensino deve priorizar que o aluno se familiarize com as regras implícitas, a fim de compreender os seus conceitos. Como afirma Silveira (2015, p. 157), “a regra matemática, quando interpretada, possibilita a compreensão do conceito que está subjacente à regra. Construir um conceito é, dessa forma, interpretar uma regra".

Para que haja essa compreensão do conceito matemático, é imprescindível que a comunicação entre professor e aluno seja estabelecida, pois, a comunicação das regras matemáticas dá-se a partir da linguagem natural do aluno, que possui regras gramaticais tais como as da linguagem matemática.

A linguagem natural pode ser uma barreira comunicativa às regras matemáticas, pois a linguagem natural tem característica polissêmica, em que uma palavra, dependendo do contexto no qual esteja inserida, possui um significado diferente e pode não corresponder ao significado apropriado da linguagem matemática, caracterizada como monossêmica.

Meira (2012) aponta que 
[...] uma expressão verbalizada pelo professor de matemática pode não possuir o mesmo significado para o aluno e isso em algumas circunstâncias pode leválo a interpretar a regra de modo equivocado, isto é, interpretar de forma que não esteja em acordo com a lógica da matemática. Assim, a expressão anunciada pelo professor, naquele momento, pode não fazer parte do jogo de linguagem do aluno, isto é, do 'universo discursivo' em que ele esteja operando e desse modo possibilita-lhe diversas interpretações (MEIRA, 2012, p. 43).

Assim, o texto matemático pode ser escrito tanto em linguagem simbólica, que consiste em códigos, gráficos, expressões algébricas e pode dizer muito com poucos símbolos, por exemplo: $(A \cup B)=\{x / x \in A$ ou $x \in B\}$, quanto em linguagem natural, na qual há termos do vocabulário carregados de expressões matemáticas, como: determine a medida da apótema de um hexágono regular inscrito numa circunferência de raio $6 \mathrm{~cm}$.

Para quem atua no ensino de matemática, é inegável que os assuntos iniciais se deem a partir do momento em que o professor aponta para o quadro e, por exemplo, afirma: observe que a medida do lado desse triângulo retângulo...; Qual o número que posso substituir aqui no x e o resultado será igual a 5?; Veja que 15 é divisível por um, por três, por cinco e por ele mesmo. Wittgenstein denominada este tipo de ensino como ensino ostensivo, em que "uma parte importante desse treinamento consistirá no fato de quem ensina mostra objetos, chama atenção da criança para eles" (WITTGENSTEIN, 1996, § 6).

De acordo com o filósofo austríaco, o professor não pode ensinar por meio da dúvida, e sim, partir de certezas. Quando ensinamos a criança a contar, não podemos querer que por si só descubra que depois de dezenove vem vinte. Os números são invenções humanas e a técnica de contagem tem que ser ensinada pelo professor. O aluno aprenderá a contar após um certo hábito com a contagem, assim poderá aprender as operações com números, mas para que isso aconteça deve ser iniciado na aprendizagem da gramática que rege os textos matemáticos (SILVEIRA, 2017, p. 54).

Wittgenstein diz que "a criança aprende, acreditando no adulto" (WITTGENSTEIN, 1969, §160) e que ela "acredita nos professores e nos livros escolares" (WITTGENSTEIN, 1969, § 263). Nesse caso, entendemos que é de fundamental importância que o uso de regras no ensino de matemática seja feito com cautela, a fim de que tenha sentido ao aluno, seja na fala do professor, seja 
na escrita do livro didático. Não ter cautela no uso de algumas expressões pode trazer implicações prejudiciais para a aprendizagem, tais como: no algoritmo da subtração, quando o professor diz que "empresta um"; na equação polinomial, é dito "o número que está multiplicando, passa para o outro lado dividindo"; na operação de multiplicação com fração, "multiplicamos o numerador com numerador e denominador com denominador";

Neste sentido, Meira evidencia que

os alunos aplicam as regras dos algoritmos e processos de resolução sem se darem conta de que não a compreenderam, apenas, reproduzem mecanicamente, porém, isso não significa que a compreensão seja algo mecânico (MEIRA, 2012, p. 44).

Lembremos que, para o filósofo, compreender é uma habilidade, é dominar uma técnica. Na docência, percebemos que somente o ato de resolver exemplos no quadro de cada tópico de um conteúdo não é condição suficiente para que o aluno compreenda o assunto. Aquele que resolve a lista de exercício em sala de aula, refaz em casa, normalmente é o aluno que terá um melhor desempenho nas atividades avaliativas, uma vez que segue as regras matemáticas daquele conteúdo estudado.

Silveira (2015) afirma que o processo de aplicação de regras não é mecânico, pois é preciso a interpretação, já que é no uso que adquire sentido. $O$ aluno interpreta a regra, projeta sentidos durante a sua aplicação e a compreende.

Em relação ao tratamento da matemática, Machado (1990) esclarece que:

Com relação à expectativa de que, na aprendizagem de qualquer assunto seria necessária uma abordagem inicial, limitada ao âmbito da técnica operatória. [...] as regras precisam ser bem conhecidas antes de se poder pensar em agir ou jogar. [...] no caso do processo de produção do conhecimento, na aprendizagem da Língua [materna] ou da Matemática, a técnica alimenta 0 significado que alimenta a técnica... e assim por diante (MACHADO, 1990, p. 115-116).

Neste sentido, Gómez-Granell (1996) aponta que

[...] as regras de escrita de números de mais de um algarismo, os algoritmos das operações, a medida de diferentes magnitudes, as operações com 
parênteses, a simplificação de frações, a procura do mínimo múltiplo comum, a resolução de equações, a resolução de integrais, etc., além de um conhecimento conceitual, o domínio de uma série de regras e convenções que também é necessário aprender e ensinar (GÓMEZ-GRANELL, 1996, p. 274)

A partir dos excertos, vemos a importância do uso de regras, levando em consideração que a regra tenha sentido ao aluno e que este construa o conceito que está implícito na regra. Assim, o que dá sentido a um código ou a uma regra é o uso que fazemos destes. Para Wittgenstein "compreender uma frase significa compreender uma linguagem. Compreender uma linguagem significa dominar uma técnica" (WITTGENSTEIN, 1996, § 199). Por exemplo, para jogar xadrez é necessário aprender regras, é importante saber o uso de cada peça. Caso o jogador utilize de outras regras, não está jogando xadrez.

Gómez-Granell (1996) traz um exemplo pertinente para esclarecer acerca do ensino de matemática para aqueles que defendem uma concepção formalista da matemática e outros que defendem que há necessidade de algum significado extra aos símbolos, algo vinculado a realidade do estudante.

Assim a autora toma como exemplo a expressão (a.b) = (b.a), que se refere à lei da comutatividade da multiplicação. Se transitar ou no nível algébrico ou no nível numérico ( $4 \times 5=5 \times 4$ assim como $3 \times 6=6 \times 3)$, a regra se confirma. No entanto, ela salienta que em uma situação específica com um determinado significado semântico, a regra deixa de ser cumprida: a expressão "4 caramelos custam 6 pesetas cada um" não é equivalente à expressão "6 caramelos custam 4 pesetas cada um". Desta forma, o professor que tenta contextualizar a matemática sempre justificando suas regras na empiria pode causar confusões gramaticais para este aluno.

No ensino de regras matemáticas, há dois tipos de proposições que devem ser explicitadas: a proposição matemática ou gramatical (é normativa, expressa norma, regra a ser seguida) e a proposição empírica (descreve fatos da realidade).

Para Glock (1998, p. 194), "a proposição gramatical não consiste em enunciar como estão as coisas, mas antes em expressar uma regra de forma exata, elas devem ser diferenciadas de enunciados empíricos”. 
Uma proposição gramatical $7+5=12$ não é nem verdadeira ou falsa; ela serve como padrão de correção que $7+5=10$ não está de acordo com a regra gramatical, pois o cálculo está errado. "Se o verdadeiro é o que é fundamentado, então o fundamento não é verdadeiro nem falso" (WITTGENSTEIN, 1969, § 205). "O que estou querendo dizer é que a matemática é normativa" (WITTGENSTEIN, [19--], § 61).

A proposição empírica tem a função descritiva e baseia-se na verificação na empiria. Quando uma criança diz a outra "sou mais alto do que tu" ou "João é filho de José", estamos diante de proposições que necessitam de verificação para serem validadas. Assim, para validar a primeira, poderíamos usar uma fita métrica para tal e, na segunda assertiva, verificar a partir de um documento oficial para comprovar a filiação paternal.

Desta forma, não validamos que 7 + 5 é igual a 12, pelo fato de que 7 laranjas mais 5 laranjas perfazem 12 laranjas; assim como $\frac{1}{2}+\frac{1}{2}=1$ não é validado pelo cálculo de maçãs, em que meia maçã mais meia maçã será uma maçã inteira; mas sim pela regra matemática $\frac{1}{2}+\frac{1}{2}=1$ que podemos validar a proposição com maçãs.

Se em uma divisão de dez bombons entre duas crianças, não necessariamente pensemos em uma divisão exata, pois, se uma das crianças queira seguir a regra de que merece mais bombons, não haverá problema. Neste sentido, Gottschalk (2008, p. 81) explica que "atividade matemática distingue-se radicalmente dos procedimentos empíricos: o cálculo não é um experimento, não é preditivo e tampouco a prova matemática se baseia em evidências empíricas". Portanto, a atividade matemática 6 dividido por 3 deve ser igual a 2, pois é uma norma.

Gómez-Granell (1996) coaduna com o esclarecimento de Gottschalk quando diz que:

Poderíamos dizer, resumindo, que os símbolos matemáticos possuem dois significados. Um deles, estritamente formal, que obedece a regras internas do 
próprio sistema e se caracteriza pela sua autonomia do real, pois a validade das suas declarações não está determinada pelo exterior (constatação empírica). E o outro significado, que poderíamos chamar de "referencial", que permite associar os símbolos matemáticos às situações reais e torná-los úteis para, entre outras coisas, resolver problemas. Isto é, o problema reside no fato de que, embora as expressões matemáticas façam, por um lado, referência a situações em que aparecem relações quantitativas - portanto, podendo ser matematizada - por outro lado, para que tais expressões pertençam ao domínio da matemática devem ser totalmente autônomas em relação aos contextos e situações específicas de referência (GÓMEZ-GRANELL, 1996, p. 264).

Em sua pesquisa, Silva (2011) desmitifica que uma proposição só teria sentido, só significaria algo, se descrevesse algo no mundo; assim, caso as proposições não "apontassem" para nada no mundo, estas consistiriam em termos sem referências e assim sem sentido. Desta forma, o professor que ensina matemática deve deixar claro para o aluno que as proposições empíricas não podem determinar como seguir regras, e sim as proposições matemáticas que determinam como agir em suas possíveis aplicações.

Neste sentido, Wittgenstein deixa indícios em sua filosofia de que há uma linha tênue entre as proposições gramaticais e proposições empíricas dependendo do contexto e salienta que a demarcação entre as proposições não é de fácil elucidação. O filósofo diz que não podemos fazer diferenciação pela forma, e sim pelo uso que tem na linguagem:

Poderia imaginar-se que algumas proposições, com a forma de proposições empíricas, tornavam-se rígidas e funcionavam como canais para as proposições empíricas que não endureciam e eram fluidas, e que esta relação se alterava com o tempo, de modo que as proposições fluidas se tornavam rígidas e vice-versa (WITTGENSTEIN, 1969, § 96).

Isto é certo: a mesma proposição pode ser tratada uma vez como coisa a verificar pela experiência, outra vez como regra de verificação (WITTGENSTEIN, 1969, § 98).

Para uma melhor compreensão dessa linha tênue, recorremos à explicação de Gottschalk (2007), na qual ela esclarece quando a proposição ora é gramatical, ora é empírica: uma mesma afirmação, como "isto é branco", pode ter ora uma função descritiva ora uma função normativa, dependendo do contexto de 
enunciação. Se for uma resposta à pergunta "o que é branco?", estará sendo empregada normativamente, enquanto em um outro contexto pode estar sendo empregada simplesmente para descrever a cor de um determinado objeto. O que é importante ressaltar nesta distinção que Wittgenstein faz em relação aos diferentes usos possíveis de uma mesma proposição é que a função exercida se mostra no próprio uso da proposição. São as circunstâncias que esclarecem o tipo de função que exercerão.

\section{Considerações finais}

O artigo teve como objetivo desmistificar a compreensão de regras no ensino de matemática sob a perspectiva da filosofia de Wittgenstein, a qual sinaliza caminhos para trabalharmos o uso de regras no processo educativo da matemática, uma vez que as pesquisas em educação matemática ainda apontam que o uso de regras torna o ensino e aprendizagem mecânica. De acordo com Meira (2012), aplicar regras mecanicamente, não significa que a compreensão é algo mecânico, pois, quando não temos dúvidas quanto ao seguimento de regras, isso se dá em virtude do treino, da prática.

Wittgenstein (1996) diz que é no uso que uma regra adquire sentido, pois o que constitui a regra é prática constante. Para Silveira (2015), o processo de aplicação da regra não é mecânico, é preciso a interpretação. O aluno interpreta a regra e projeta sentido durante a sua aplicação e compreende. Neste segmento, Machado (1990) ressalta que na aprendizagem de qualquer assunto é necessária uma abordagem inicial no âmbito da técnica operatória. As regras precisam ser bem conhecidas antes de se poder pensar em agir ou jogar.

Assim, mostramos que as proposições são classificadas em: proposições matemáticas, consideradas normativas, regras a serem seguidas e as proposições empíricas, aquelas que descrevem fatos da realidade. Assim, esclarecemos que o professor que ensina matemática deve deixar claro para o aluno que as proposições empíricas não podem determinar como seguir regras, e sim são as 
proposições matemáticas que determinam como agir em suas possíveis aplicações.

Defendemos também que, para que haja a compreensão do conceito matemático, é imprescindível que a comunicação entre professor e aluno seja estabelecida, pois a comunicação das regras matemáticas dá-se a partir da linguagem natural do aluno, que possui regras gramaticais tais como as da linguagem matemática. Muitos dos equívocos de má interpretação da regra podem ser esclarecidos a partir do jogo de linguagem estabelecido entre os principais protagonistas da sala de aula.

\section{Referências}

DALL'AGNOL, Darlei. Sobre a conexão entre regras e ações: Uma análise do $§ 198$ das Investigações Filosóficas de Wittgenstein. In: DI NAPOLI, Ricardo Bins; ROSSATO, Noeli; FABRI, Marcelo (Org.). Ética \& Justiça. Santa Maia: Palloti/CNPq, 2003. p. 41-52. $1 \mathrm{v}$.

GÓMEZ-GRANELL, Carmen. Aquisição da Linguagem Matemática: símbolo e significado. In: TEBEROSKY, Ana; TOLCHINSKY, Liliana (Org.). Além da alfabetização fonológica, textual e material. São Paulo: Ática, 1996. p. 257-282.

GOTTSCHALK, Cristiane M. C. Três concepções de significado na matemática: Bloor, Granger e Wittgenstein. In: MORENO, Arley R. (Org.). Wittgenstein: aspectos pragmáticos. Campinas: UNICAMP, 2007. p. 95-133. 49 v.

GOTTSCHALK, Cristiane M. C. A construção e transmissão do conhecimento matemática sob uma perspectiva wittgensteiniana. Caderno Cedes, Campinas, v. 28, n. 74, p. 75-96, jan./abr. 2008.

GLOCK, Hans-Johann. Dicionário Wittgenstein. Rio de Janeiro: Jorge Zahar Editor, 1998.

MACHADO, Nílson José. Matemática e Língua Materna: análise de uma impregnação mútua. São Paulo: Cortez, 1990.

MACHADO, Cacilda Tenório Oliveira. Concepções epistemológicas e experiências de professores de matemática sobre números fracionários: as implicações em suas práticas na 5a série do ensino fundamental. 2007. 132 f. Dissertação (Mestrado em Ensino das Ciências) - Programa de Pós-Graduação em Ensino das Ciências, Universidade Federal Rural de Pernambuco, Recife, 2007.

MEIRA, Janeisi de Lima. Labirintos da compreensão de regras em matemática: um estudo a partir da regra de três. 2012. 99 f. Dissertação (Mestrado em Educação em 
Ciências e Matemáticas) - Programa de Pós-Graduação em Educação em Ciências e Matemáticas, Instituto de Educação Matemática e Científica, Universidade Federal do Pará, Belém, 2012.

SILVA, João Esteves da. Cinco Ensaios sobre Wittgenstein. Lisboa: Centro de Filosofia das Ciências da Universidade de Lisboa, 2010.

SILVA, Paulo Vilhena da. $\mathbf{O}$ aprendizado de regras matemáticas: uma pesquisa de inspiração wittgensteiniana com crianças da 4⿳亠丷a série no estudo de divisão. 2011. 102 f. Dissertação (Mestrado em Educação em Ciências e Matemáticas) - Programa de PósGraduação em Educação em Ciências e Matemáticas, Instituto de Educação Matemática e Científica, Universidade Federal do Pará, Belém, 2011.

SILVEIRA, Marisa Rosâni Abreu da. Interpretação de textos na aprendizagem da matemática. In: FLORES, Claudia Regina; CASSIANI, Suzani. (Org.). Tendências contemporâneas nas pesquisas em educação matemática e científica: sobre linguagens e práticas culturais. Campinas: Mercado de Letras, 2013. p. 131-154.

SILVEIRA, Marisa Rosâni Abreu da. Matemática, discurso e linguagens: contribuições para a educação matemática. São Paulo: Livraria da Física, 2015.

SILVEIRA, Marisa Rosâni Abreu da. Jogos de linguagem entre professor e alunos: possibilidades de aprender e ensinar matemática. Unión (San Cristobal de La Laguna), v. 50, p. 78-91, 2017.

SCHIMITZ, Renata M. C. Formação de professores que ensinam matemática nos anos iniciais. In: CONGRESSO NACIONAL DE EDUCAÇÃO, 13., 2017, Curitiba. Anais... Curitiba: PUCPRess - Editora Universitária Champagnat, 2017. p. 5210-5222.

WITTGENSTEIN, L. Da Certeza (DC). Lisboa: Edições 70, 1969.

WITTGENSTEIN, L. Investigações Filosóficas (IF). São Paulo: Editora Nova Cultural,1996.

WITTGENSTEIN, L. Observações sobre os Fundamentos da Matemática (OFM). [S.I.: s.n., 19--]. 